\title{
Violência social e violência contra a pessoa idosa: Duas faces da mesma essência
}

\author{
Social violence and violence against elderly people: Two faces of the same essence \\ Violencia social y violencia contra ancianos: Dos caras de la misma esencia
}

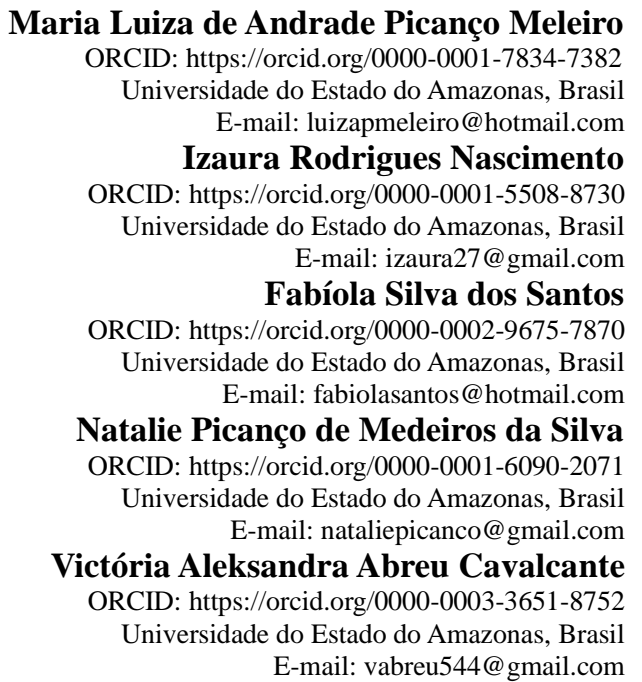

\begin{abstract}
Resumo
Apoiado em pesquisa bibliográfica de especialistas na área de violência e violência contra idosos, assim como em documentos oficiais do governo brasileiro, o artigo objetiva trazer à discussão a problemática da violência e da violência sofrida pela pessoa idosa no contexto brasileiro. O Brasil passa por mudanças significativas e profundas em sua estrutura etária e o contingente de idosos só tende a aumentar. Concomitante a esse aumento, crescem também, na mesma proporção, os desafios que o país tende a enfrentar face a esta realidade. É realizada uma abordagem de cunho sociológico sobre o tema da violência com o objetivo de compreender, situar, conceituar, caracterizar e problematizar a violência dentro do contexto social e sua manifestação na sociedade. Para tal nos valemos das ideias de Norbert Elias, Michel Foucault, Max Weber, Michel Missi, Willem Schinkel, Norberto Bobbio, Edgar Morin, Thomas Hobbes, dentre outros. O texto conclui afirmando que a violência entre seres humanos parece fazer parte da própria história da humanidade, e que violência doméstica e os maus-tratos a idosos não devem ser entendidos fora do contexto da violência social/estrutural em que os indivíduos e as comunidades estão inseridos. É necessário, portanto, que o conjunto da sociedade tenha uma visão mais ampliada, que permita a percepção de que o enfrentamento da violência contra o idoso ultrapassa a análise criminal e exige a aplicação dos princípios que norteiam a Política Nacional do Idoso e o Estatuto do Idoso.
\end{abstract}

Palavras-chave: Violência; Violência contra idosos; Envelhecimento populacional.

\begin{abstract}
Based on bibliographical research of specialists in the area of violence and violence against the elderly, as well as in official documents of the Brazilian government, the article aims to bring to the discussion the problem of violence, mistreatment, and abuse suffered by the elderly in the Brazilian context. Brazil undergoes significant and profound changes in its age structure, and the contingent of the elderly only tends to increase. Concomitant with this increase, the same number of challenges that the country tends to face in the face of this reality is growing. A sociological approach is carried out on the theme of violence in order to understand, situate, conceptualize, characterize and problematize violence within the social context and its manifestation in society. To this end, we use the ideas of Norbert Elias, Michel Foucault, Max Weber, Michel Missi, Willem Schinkel, Norberto Bobbio, Edgar Morin, Thomas Hobbes, among others. The text concludes by stating that violence between human beings seems to be part of humanity's own history, and that domestic violence and abuse of the elderly should not be understood outside the context of social / structural violence in which individuals and communities are inserted. It is, therefore, necessary for society as a whole to have a broader view that allows the perception that coping with violence against the elderly goes beyond criminal analysis and requires the application of the principles that guide the National Policy on the Elderly and the Statute of the Elderly.
\end{abstract}


Keywords: Violence; Violence against the elderly; Aging population.

\section{Resumen}

Apoyado en la investigación bibliográfica de especialistas en el campo de la violencia y la violencia contra las personas mayores, así como en documentos oficiales del gobierno brasileño, el artículo tiene como objetivo traer a la discusión el tema de la violencia y la violencia que sufren los ancianos en el contexto brasileño. Brasil está atravesando cambios significativos y profundos en su estructura de edades y el número de personas mayores solo tiende a aumentar. Concomitante a este incremento, también crecen, en la misma proporción, los desafíos que tiende a enfrentar el país ante esta realidad. Se realiza un abordaje sociológico sobre el tema de la violencia con el objetivo de comprender, ubicar, conceptualizar, caracterizar y problematizar la violencia dentro del contexto social y su manifestación en la sociedad. Para ello, utiliza las ideas de Norbert Elias, Michel Foucault, Max Weber, Michel Missi, Willem Schinkel, Norberto Bobbio, Edgar Morin, Thomas Hobbes, entre otros. El texto concluye afirmando que la violencia entre seres humanos parece ser parte de la propia historia de la humanidad, y que la violencia intrafamiliar y el maltrato a las personas mayores no deben entenderse fuera del contexto de violencia social / estructural en el que se insertan los individuos y las comunidades. Es necesario, por tanto, que la sociedad en su conjunto cuente con una visión más amplia, que permita la percepción de que el enfrentamiento de la violencia contra las personas mayores va más allá del análisis criminal y requiere de la aplicación de los principios que orientan la Política Nacional y el Estatuto do Idoso.

Palabras clave: Violencia; Violencia contra las personas mayores; Envejecimiento poblacional.

\section{Introdução}

A Constituição da República Federativa do Brasil de 1988 foi um marco rumo à conquista dos direitos Sociais do povo brasileiro. Seu caráter cidadão teve como referência internacional a Declaração Universal dos Direitos Humanos, proclamada por meio da Resolução da Assembleia Geral das Nações Unidas 217-A em 10 de dezembro de 1948, e indica o respeito aos direitos e liberdades da pessoa humana como o ideal comum a ser atingido por todos os povos e todas as nações (Instituto de Pesquisa Econômica Aplicada [IPEA], 2016). A Cidadania e a dignidade da pessoa humana como fundamentos do Estado Democrático de Direito são os pilares que alicerçam nossa Constituição (CF/1988).

Os direitos dos idosos não ficaram de fora do bojo constitucional. No Artigo 229, a Lei define que "[...] os pais têm o dever de assistir, criar e educar os filhos menores, e os filhos maiores têm o dever de ajudar e amparar os pais na velhice e, carência ou enfermidade". E na sequência, o Artigo 230 estabelece que a família, a sociedade e o Estado têm o dever de amparar as pessoas idosas, assegurando sua participação na comunidade, defendendo sua dignidade e bem-estar e garantindolhes o direito à vida.

Em janeiro de 1994 foi promulgada a Política Nacional do Idoso (Lei nº 8.842/1994), com o objetivo principal de assegurar os direitos sociais do idoso, criando condições para promover sua autonomia, integração e participação efetiva na sociedade. Contudo, o mais esperado e festejado arcabouço jurídico direcionado à população idosa brasileira foi, sem dúvida, a promulgação do Estatuto do Idoso (Lei no 10.741/2003). Com o compromisso de fomentar, garantir e promover os direitos da pessoa idosa com o envelhecimento ativo e saudável, dignidade, independência, protagonismo e autonomia, o Estatuto do Idoso representa um marco jurídico para a proteção da população idosa brasileira.

Após a visibilidade constatada a partir dos índices de violência e maus-tratos sofridos pelos idosos brasileiros, em 2011, foi promulgada a Lei $\mathrm{n}^{\circ} 12.461 / 11$, que reformula o artigo $\mathrm{n}^{\mathrm{o}} 19$ do Estatuto do Idoso (Lei $\mathrm{n}^{\mathrm{o}} 10.741 / 2003$ ), tornando obrigatória a notificação por parte dos profissionais de saúde, às autoridades sanitárias, Ministério Público, Autoridade Policial, Conselhos Municipal, Estadual e Nacional do Idoso, em caso de suspeitas ou confirmação de violências contra os idosos.

Percebe-se, dessa forma que o Estado brasileiro possui um arcabouço legal alinhado às exigências e tratados internacionais que objetivam dar proteção ao idoso e resguardar os seus direitos fundamentais. Na prática, contudo, o que se vê, infelizmente, são esses direitos sendo lesados e em muitos casos os idosos sendo violentados de forma cruel, e às vezes, até 
letal.

No entanto, não é possível pensar na problemática da violência contra a pessoa idosa sem antes refletir nos aspectos da violência partindo de uma concepção holística, de abrangência histórica bem como suas múltiplas interfaces. Para tanto foi realizada uma abordagem de cunho sociológico sobre o tema da violência com o objetivo de compreender, situar, conceituar, caracterizar e problematizar a violência dentro do contexto social e sua manifestação na sociedade.

$\mathrm{O}$ artigo objetiva trazer à discussão a problemática da violência, maus-tratos e abusos sofridos pela pessoa idosa dentro de um contexto geral da violência social.

Além desta breve introdução, demonstra-se na próxima seção a metodologia utilizada na construção do artigo. Na sequência apresentam-se informações e dados epidemiológicos, evidenciando a representatividade dos idosos na pirâmide etária do Brasil bem como a magnitude e a velocidade dos câmbios populacionais pelos quais a América Latina e o Brasil têm experimentado. O tópico seguinte, convida a refletir sobre a violência desde a sua concepção história como um problema social. Para os autores encerrar a noção de violência numa definição fixa e simples é expor-se a reduzi-la, a compreender mal sua evolução e sua especificidade histórica, em razão de um caráter mutante. Além disso, parte das dificuldades para conceituar a violência vem do fato de ela ser um fenômeno da ordem do vivido, cujas manifestações provocam ou são provocadas por uma forte carga emocional de quem a comete, de quem a sofre e de quem a presencia. Os eventos violentos sempre passaram e passam pelo julgamento moral da sociedade. Na sequência aborda-se a violência e maus-tratos sofridos pelos idosos com ênfase na tipificação e classificação das categorias de violências sob o ponto de vista legal e breve reflexão dos contextos familiares onde essas violências se reproduzem enfatizando que violência doméstica e os maus-tratos a idosos não devem ser entendidos fora do contexto da violência social/estrutural em que os indivíduos e as comunidades estão inseridos.

As considerações finais sumarizam o presente trabalho.

\section{Metodologia}

Trata-se de uma pesquisa qualitativa, realizada por meio de estudo bibliográfico (Lakatos, 2017), orientada pelos seguintes descritores: violência na visão sociológica e violência no Brasil por meio da qual foram identificados e selecionados alguns dos autores/obras recorrentemente referidos em planos de curso sobre sociologia da violência; o descritor "violência contra a pessoa idosa no Brasil", orientou a identificação de autores/obras sobre esse tema. Também foi realizado estudo de documentos produzidos por instituições referenciais no Brasil. A seguir indicamos os temas abordados e suas respectivas fontes.

A análise sociológica da violência desde sua concepção histórica foi alicerçada nos pressupostos teóricos de Émile Durkheim (1858-1917) de acordo com Aron (1967); Thomas Hobbes (1588-1679), (Hobbes, 2003); Marx Weber (1864-1920), (Weber, 1991); Norbert Elias (1897-1990), (Elias, 1990;1993); Simone de Beauvoir (1908-1986), (Beauvoir, 2018); Norberto Bobbio (1909-2004), (Bobbio, 2004); Michel Foucault (1926-1984), (Foucault, 1997); Zygmunt Bauman (1927-2017), (Bauman, 2001); Edgar Morin (1921), (Morin, 2010); Michel Wieviorka (1946), (Wieviorka, 2018) e Willem Schinkel (1976), (Schinkel , 2010). A violência no contexto brasileiro e a violência contra a pessoa idosa fundamentaram-se especialmente em Odália (1983), Santos (2004); Bretas (1991); Adorno (1993); Zaluar (1999), Sposito (2001); Misse et al, (2009), Misse (2016); Santos (2004); Salas (2001); (Camarano, 2004; 2016); Pasinato et al. (2006) e Minayo (2010; 2014; 2017). Já os aspectos que envolvem as questões do envelhecimento populacional, tanto no Brasil quanto na América Latina tiveram como fonte de pesquisas os dados, informações e análises do Centro Latino-Americano e Caribenho de Demografia (CELADE), Comissão Econômica da para a América Latina e o Caribe (CEPAL, do Instituto de Pesquisa Econômica Aplicada (IPEA) e do Instituto 
Brasileiro de Geografia e Estatística (IBGE) além das contribuições de Brito (2020) e Meleiro (2021).

\section{Resultados e Discussão}

\subsection{A nova era demográfica}

Uma das maiores conquistas culturais de um povo em seu processo de humanização é o envelhecimento de sua população, que refletem uma melhoria das condições de vida, nos seus mais variados aspectos. De acordo com projeções do Fundo de Populações, órgão ligado às Nações Unidas, uma em cada nove pessoas no mundo tem 60 anos ou mais, e estima-se um crescimento para 1 em cada 5 por volta de 2050, ou seja, passará de 11\% para 20\%, duplicando sua população. Em 2050 também será o ano em que pela primeira vez haverá mais idosos que crianças menores de 15 anos no planeta. Projeta-se que o número de idosos, alcance 1 bilhão por volta do ano de 2022 e mais que duplique em 2050, alcançando 2 bilhões de pessoas ou $22 \%$ da população global. Em 2021 teremos pela primeira vez na história o número de pessoas com mais de 60 anos maior que o de crianças até cinco anos e a expectativa de vida global que em 2015 era de 66 anos, passará para 72, em 2050, segundo a Organização Mundial de Saúde (Programa das Nações Unidas para o Desenvolvimento [PNUD], 2017).

Estudos da Comissão Econômica para a América Latina e Caribe (CEPAL) apontam que o comportamento demográfico na América Latina e Caribe, ao mesmo tempo em que se alinha e converge com outras regiões do mundo, também possui características particulares que o distingue. Tais características são frutos do momento em que se iniciaram as transições demográfica, epidemiológica e urbana de seus países, a velocidade em que ocorreu, a diversidade de situações entre e dentro deles, e especialmente o contexto de heterogeneidade estrutural e sua principal consequência no plano social, na desigualdade, que se expressa com maior persistência e profundidade que outras regiões do mundo. Tal estudo prevê que o número de habitantes na América Latina e no Caribe irá aumentar de 512 milhões de pessoas no ano 2000, para 734 milhões de pessoas em 2050 (CEPAL, 2013a).

A magnitude e a velocidade dos câmbios populacionais pelos quais a América Latina e o Caribe têm experimentado nos últimos anos são de tal envergadura que a División de Población do Centro Latinoamericano y Caribeño de Demografía (CELADE) chegou a denominar de "nueva era demográfica": passando de intenso crescimento populacional na segunda metade do século XX, para projeções que apontam modificações na estrutura por idade da população, com o avanço crescente e profundo do processo de envelhecimento em todos os países, já na primeira metade do século XXI, ou seja, a América Latina e Caribe passarão do boom demográfico para as sociedades envelhecidas ${ }^{l}$, com todas as implicações e desafios que esta realidade traz consigo (CELADE, 2014).

Tais mudanças são resultantes principalmente da redução das taxas de fecundidade e o aumento da longevidade, segundo os estudos. A taxa de fecundidade na América Latina e o Caribe eram uma das mais altas do mundo com cerca de seis filhos por mulher entre 1950 e 1955. Em 2015, a taxa já era de 2,2 filhos por mulher, índice abaixo da média mundial $(2,3)$. Já a expectativa de vida na região entre 1950 e 1955 era de 55,7 anos, dez anos a menos que a média dos países desenvolvidos. Entre 2010 e 2015, essa cifra subiu para 74,7 anos, um aumento que se deve em grande parte à redução da mortalidade infantil e das políticas sociais voltadas para os idosos (CELADE, 2014).

No Brasil, a mudança na demografia está ocorrendo de forma ainda mais acentuada. Conforme o Relatório Mundial de Saúde e Envelhecimento da Organização Mundial da Saúde - OMS (2015), o número de pessoas com mais de 60 anos no país deverá crescer muito mais rápido do que a média internacional. Enquanto a quantidade de idosos vai duplicar no mundo até o ano de 2050, ela quase triplicará no Brasil. A porcentagem atual, de 14\% de idosos, deve alcançar os $30 \%$ até a metade

${ }^{1}$ Sociedades Envelhecidas - conforme a OMS, essa classificação é dada aos países com mais de 14\% da população constituída de idosos, como são, atualmente, França, Inglaterra e Canadá, por exemplo. 
do século. Ou seja, logo seremos considerados uma nação envelhecida, de acordo com a classificação da Organização Mundial da Saúde (OMS, 2015).

Tomemos como exemplo o levantamento e projeções realizados pela CEPAL no final do ano de 2014. Segundo os estudos, em 1950 o Brasil tinha uma população idosa² de 4,9\% do total de sua população, contra 7\% da Argentina. Na América Latina esse percentual era de 5,6\%. Em 2015, o aumento dos idosos em relação a 2050 foi de 98,2\% na América Latina, 117,4\% na Argentina e 138,8\% no Brasil. Em 2030, o Brasil terá 18,9\%, contra 17,7\% na Argentina e 16,6\% na América Latina e em 2060, o Brasil terá 33,5\% de idosos, com um contingente em torno de 83 milhões de pessoas (CEPAL, 2013a, 2013b). Apenas para efeito de compreensão da magnitude da situação, esse número é quase duas vezes a população total da Argentina dos dias de hoje.

Segundo relatório do Instituto de Pesquisa Econômica Aplicada - IPEA, uma das razões para o aumento expressivo da quantidade de idosos no Brasil é que nos últimos anos o governo brasileiro tem promovido avanços institucionais e nas políticas públicas voltadas à promoção dos direitos humanos das pessoas idosas. Muito em função da mobilização dos próprios idosos e da sociedade civil, foi possível estruturar políticas mais abrangentes para a promoção e efetivação dos direitos dos idosos e criar instituições adequadas para tal (IPEA, 2016).

Apesar dos esforços, a situação demográfica do Brasil aponta para um agravamento ainda maior. As mudanças na estrutura etária da população afetam as economias na medida em que alteram a distribuição das pessoas em idades de maior e menor produtividade laboral em comparação com seu consumo. Já em 2032, segundo a CEPAL, a população com mais de 60 anos será maior que a de 0 a 14 anos e o contingente de idosos tende somente a aumentar, trazendo sérias consequências, pois à medida que a distribuição etária da população se torna mais concentrada nas idades mais velhas o coeficiente de apoio econômico ${ }^{3}$ cai acentuadamente, representando crescentes desafios econômicos e fiscais para o Brasil.

O estudo da Organização das Nações Unidas (ONU) anteriormente citado, alerta aos países latino-americanos sobre os novos desafios no futuro muito próximo, por conta do envelhecimento populacional, e as medidas a serem tomadas, que dependerão em grande parte tanto do nível macroeconômico, - por meio de regimes de transformação produtiva e de tributação progressiva -, como do nível político, por meio de uma melhor educação e proteção social.

O fato é que o envelhecimento populacional é uma realidade em todos os países, em maior ou menor grau, e não obstante às medidas necessárias de enfrentamento que deverão estar na pauta de todos os gestores, no que dizem respeito ao equilíbrio econômico e fiscal, estudar o envelhecimento populacional é tão importante quanto estudar outros grandes fenômenos que a humanidade está vivendo. Se o nosso objetivo é viver com qualidade é fundamental participar da reflexão e do debate de todas as questões que envolvem esse processo.

Uma das questões que se quer debater diz respeito a defesa dos plenos direitos conquistados pelos idosos. E nesse contexto, a violência e maus-tratos sofridos por eles têm se manifestado como grave forma de violação aos seus direitos, tratando-se, portanto, de um fenômeno social abrangente, às vezes difuso, cuja conscientização social é unânime em qualificar essa violência como um atentado aos direitos humanos.

Antes que se adentre especificamente na temática da violência contra os idosos, façamos breve análise sobre a violência como problema social.

\subsection{A violência como problema social}

De acordo com Minayo, Souza e Paula (2010) o termo violência é de origem latina, vem da palavra vis, que quer dizer força e se refere às noções de constrangimento e de uso da superioridade física sobre o outro. No seu sentido material, o termo

\footnotetext{
${ }^{2}$ População Idosa - A partir de 60 anos.

${ }^{3}$ Coeficiente de apoio econômico - relação entre população produtora/população consumidora.
} 
parece neutro, mas quem analisa os eventos violentos descobre que eles se referem a conflitos de autoridade, a lutas pelo poder e a vontade de domínio, de posse e de aniquilamento do outro ou de seus bens.

Para os mesmos autores, encerrar a noção de violência numa definição fixa e simples é expor-se a reduzi-la, a compreender mal sua evolução e sua especificidade histórica, uma vez que possui um caráter mutante. Nesse sentido a violência designa, pois - de acordo com épocas, locais e circunstâncias - realidades muito diferentes. Da mesma forma, Nilo Odália (1983, p. 15) assevera: "a violência não é o apanágio de uma época". E continua: "O viver em sociedade foi sempre um viver violento. Por mais que recuemos no tempo, a violência está sempre presente, ela sempre aparece em suas várias faces" (p. 13).

A maior parte das dificuldades para conceituar a violência vem do fato de ela ser um fenômeno da ordem do vivido, cujas manifestações provocam ou são provocadas por uma forte carga emocional de quem a comete, de quem a sofre e de quem a presencia. Os eventos violentos sempre passaram e passam pelo julgamento moral da sociedade.

Santos (2004, p. 8), assinala que somente nos anos 1990, a temática da violência veio a “[...] tornar-se um problema social e uma questão sociológica no estado brasileiro". Diversos estudos produzidos principalmente por Bretas (1991), ao realizar uma revisão na pesquisa recente do crime na historiografia brasileira; Adorno (1993), ao abordar um recorte temático da criminalidade urbana violenta; Zaluar, (1999), quanto traz suas concepções sobre violência e crime; Sposito (2001), ao sintetizar um balanço da pesquisa sobre violência escolar no Brasil e Lima, Misse e Miranda (2000), quando realizam uma bibliografia da violência, criminalidade, segurança pública e justiça criminal no Brasil. A partir desses autores pode-se contextualizar, o estado da arte dos estudos sociológicos sobre crime, violência, polícias, poder judiciário, fenômenos da violência na escola e segurança pública. Tais estudos também possibilitaram, em razão de sua diversidade regional, mapear e comparar cidades e Estados, acrescendo a visibilidade social e a compreensão sociológica das conflitualidades na sociedade brasileira (Santos, 2004). Ao abordar o tema da violência e dilemas do controle social nas sociedades da "modernidade tardia", o autor assevera que Brasil do século XXI está vivendo num contexto de violência difusa. Tal fenômeno é, em larga medida, legitimada pela consciência coletiva, instituindo-se como norma social, ainda que controversa e polêmica. A ideia de violência difusa, conforme salientado pelo autor, contrapõe-se ao conceito de violência do sociólogo francês Émile Durkheim (18581917). Durkheim considerava o crime um fenômeno social normal, uma vez que em toda a sociedade, um certo número de crimes é cometido e, por consequência, se nos referimos ao que se passa regularmente, o crime não é um fenômeno patológico. Ainda assim, o crime era considerado por Durkheim uma ruptura com a consciência coletiva, razão pela qual sofre punição pela lei penal (Aron, 1967).

O sociólogo francês Michel Wieviorka, em recente entrevista concedida na cidade do México no ano de 2018 considerou que, para abordar o tema da violência há a necessidade de tomar em conta os processos de objetivação e subjetivação dos sujeitos considerados violentos, a perda dos sentidos, sua reconstrução, sua ideologia, sua religião e assim por diante. Wieviorka se posiciona dentro de uma tradição antiestruturalista, que estabelece uma ideia de relação de condicionamento recíproco entre sentido e sujeito: o sujeito produz sentido e o sentido produz sujeito, numa relação biunívoca. Assinala que a violência hoje já é um tema bastante conhecido pelas ciências sociais, e coube a ela a exitosa tarefa da sua problematização. Contudo, a saída da violência não deve ser uma missão atribuída às ciências sociais e sim aos diversos atores como experts, planejadores, médicos, psiquiatras, psicanalistas dentre outros intelectuais (Wieviorka, 2018).

Em outra entrevista concedida no Rio de Janeiro ao professor da Universidade Federal do Rio de Janeiro (UFRJ), Michel Misse e outros sociólogos no ano de 2009, Wieviorka afirma que uma definição objetiva para a violência é impossível, porque o que seria violento para um sujeito, para um país, não seria para o outro. O que seria violento para a sociedade brasileira hoje, talvez não seja mais em 30 anos, e o que será violento daqui a 30 anos talvez não seja o que era violento hoje em nossas concepções. Para ele, nós passamos o tempo relativizando a violência. Então, o que temos de forma permanente é o 
sentimento de que a violência é relativa. Mas se a violência é unicamente relativa, ou seja, se ela fosse unicamente produto da subjetividade individual ou coletiva, então não poderíamos discuti-la, analisá-la. Se um diz "isso é violento" e o outro "não, não é violento", então, não podem discutir o problema. E, consequentemente, o relativismo puro é inaceitável. Então, como fazer quando uma definição objetiva é tão difícil de ser encontrada e uma definição subjetiva ou relativista é inaceitável? É preciso encontrar acomodações, é preciso negociar consigo mesmo, circular, ter muita flexibilidade e não impedir a reflexão. Então é preciso que se encontre alguma coisa que se permita introduzir uma objetividade determinada, sempre deixando um certo espaço à relatividade. É difícil, mas não é impossível, segundo ele. É, entretanto, um problema real (Misse, et al. 2009).

$\mathrm{Na}$ mesma entrevista, Wieviorka é enfático ao afirmar que é possível se opor à violência sem violência. Considera que há as pessoas que teorizaram essa ideia, como Gandhi e todos aqueles que dizem que é preciso ser não violento. É uma primeira resposta. A segunda resposta não é se opor à violência pela não violência, mas se opor à violência dizendo que um só ator tem o seu monopólio legítimo, o Estado.

É, de certa forma, a resposta do teórico, político e filósofo inglês Thomas Hobbes (1588-1679), que na obra Leviatã (1651), defende a tese inspirada em uma figura mitológica, que é uma serpente que fez um acordo com os homens. Nela explanou os seus pontos de vista sobre a natureza humana e sobre a necessidade de um governo e de uma sociedade fortes. Thomas Hobbes considerava que a natureza humana é má e defendia a ideia segundo a qual os homens só podem viver em paz se concordarem em submeter-se a um poder absoluto e centralizado. O Estado não pode estar sujeito às leis por ele criadas pois isso seria infringir sua soberania (Hobbes, 2003).

Já, para o sociólogo alemão Norbert Elias (1897-1990), há a necessidade de distinguir natureza e cultura e todas essas questões fazem parte do que ele denominou de processo civilizatório. Em O processo civilizatório, Elias (1990) demonstrou como os padrões europeus pós-medievais de violência, comportamento sexual, funções corporais, etiqueta à mesa e formas de discurso foram gradualmente transformados pelo crescente domínio da vergonha e do nojo, atuando para fora de um núcleo cortesão de etiqueta. $\mathrm{O}$ autocontrole era cada vez mais imposto por uma rede complexa de conexões sociais desenvolvidas por uma autopercepção psicológica, que o criador da psicanálise Sigmund Freud (1856-1939), cunhou como "superego"4. O segundo volume de O processo civilizatório (Elias, 1993) aborda as causas destes processos e os reconhece nas cada vez mais centralizadas e diferenciadas interconexões na sociedade.

Elias realizou um aprofundamento histórico, ou seja, resgatou a história de uma palavra - civilidade -, do francês “civilité” para compreender os padrões de comportamento e da expressão de sensibilidade e emoções da sociedade ocidental. Neste retrocesso ele encontra a origem da palavra em um Tradado do teólogo e humanista neerlandês Erasmo de Roterdã (1466-1536), de 1530, com o título “da civilidade para crianças”, que versam como alguém civilizado deveria se comportar nas mais diversas ocasiões. A ideia de Erasmo de Roterdã era transmitir alguns valores e comportamentos designados como civilizados para separar esses daqueles chamados de bárbaros ou incivilizados. Segundo Elias, esse texto ganhou tanta forca e notoriedade que a palavra civilité foi traduzida para outras línguas. Logo, ser civilizado passou a significar ter autorregulação e saber controlar seus impulsos (Elias, 1990).

Considera Norbert Elias que sociedade ocidental, através da nobreza e do cristianismo, foi fundada nesses pilares de civilização. Todo o indivíduo que não se comporta de certa forma é visto como incivilizado (Elias, 1990).

Ao fazer esse resgate das emoções humanas, Elias faz o que se considera uma sociologia histórica, ou seja, uma sociologia de longa duração, pois, procura no passado as origens do comportamento no presente. Isso só se faz possível por conta de um outro conceito de Norbert Elias, o de figuração ou configuração. Ele considera que tudo acontece através de um processo social. Nada está pronto e nada surge do nada. Tudo o que percebemos na sociedade é originário de um processo

${ }^{4}$ Superego é o aspecto moral da personalidade do indivíduo, de acordo com a Teoria da Psicanálise de Sigmund Freud. O superego é responsável por "domar" o Id, ou seja, reprimir os instintos primitivos com base nos valores morais e culturais. 
social. Ao pensar assim, conseguimos nos distanciar um pouco do momento presente e temos a possibilidade de vasculhar ao longo da história como chegamos aqui. O presente condena, no passado, a violência; mas, como afirma Elias, sem a violência o processo civilizador não teria existido: "Sem ações violentas, sem as forças propulsoras da livre competição, não teria havido monopólio de força e, destarte, nenhuma pacificação, nenhuma supressão e controle da violência em grandes áreas." (Elias, 1993, p. 139).

Elias chama atenção para o fato de que todo esse processo só se torna importante quando acreditamos que não existe um indivíduo isolado tampouco uma sociedade centralizadora. O que existe segundo ele é uma figuração ou configuração social. Para Elias a sociedade é uma figuração constituída de números indivíduos fundamentalmente interdependentes, ou seja, tributários dependentes uns dos outros. Pensar através da noção de configuração é perceber o indivíduo como alguém, cujas margens de manobra, é limitada porque vive com muitas outras pessoas, que também têm necessidades, estabelecem objetivos e tomam decisões. Ou seja, a ação de um indivíduo está sempre limitada pela ação do outro.

Semelhante à forma como Michel Foucault (1926-1984) e Marx Weber ${ }^{6}$ (1864-1920) entendem poder, Elias trabalhao como algo que não se possui, mas que tem concretude. Todavia, o exercício de poder, em Elias, pressupõe o controle preponderante de um grupo social sobre coisas, objetos e/ou pessoas. Portanto, em Elias, “[...] o conceito de poder deixou de ser uma substância para se transformar numa relação entre duas ou mais pessoas e objetos naturais; assim, o poder é um atributo destas relações que se mantêm num equilíbrio instável de forças" (Sallas, 2001, p. 219).

Assim tomado, o poder advém basicamente das relações humanas as mais variadas, e, com isso, ele pode assumir diversas formas. Como consequência, temos que certos grupos sociais ou mesmo certos indivíduos "[...] podem reter ou monopolizar aquilo que os outros necessitam, como por exemplo, comida, amor, segurança, conhecimento, etc. Portanto, quanto maior as necessidades desses últimos, maior é a proporção de poder que detêm os primeiros" (Elias, 1994 como citado em Gebara \& Lucena, 2005, p. 01).

Desta forma, Elias amplia a noção de poder, para além da visão estatal ou econômica, vez que não a reduz às relações entre senhores e servos, dominadores e dominados, mas a estende nas que podem ocorrer entre indivíduos de uma mesma família, entre membros de bairros vizinhos. Esta abrangência das relações de poder é discutida com maior profundidade em capítulo sobre Modelos de Jogos de "Introdução à Sociologia" (1980), que indica claramente a presença relacional de poder com o exemplo da "força relativa dos jogadores".

Norbert Elias ressalta que a civilização, enquanto processo, conta com mecanismos de controle da violência e com a própria violência para exercê-los. Conquanto, estas três esferas (Processo civilizatório, controle e violência) estão interligadas e coabitam numa perspectiva relacional. Por isso mesmo, "os termos 'civilizado' e 'incivil' não constituem uma antítese daquela existente entre o 'bem' e o 'mal', mas representam, sim, fases de um desenvolvimento que [...] ainda continua" (Elias, 1990, p. 73).

Dessa forma, Elias (1990, p. 95) identifica “[...] o padrão de hábitos e comportamento a que a sociedade, em uma dada época, procurou acostumar o indivíduo". Desta feita, a mudança de comportamento não está influenciada por questões de ordem científica, religiosa ou de higiene, ela é uma consequência social, verificada porque "[...] a estrutura alterada da nova classe expõe cada indivíduo [...] às pressões dos demais e do controle social" (Elias, 1994, p. 91 como citado em Gebara \& Lucena, 2005).

O sociólogo e professor brasileiro Michel Misse é um dos estudiosos que se dedica aos estudos da violência. Ao

\footnotetext{
${ }^{5}$ Para Michel Foucault não existe o poder, mas sim relações de poder, que através de seus mecanismos atua como uma força coagindo, disciplinando e controlando os indivíduos. Considera que na modernidade, à medida em que foram mudando as relações sociopolíticas e econômicas, também foram sendo produzidas novas relações de poder, mais adequadas às necessidades do poder dominante (Foucault, 1997).

${ }^{6}$ Max Weber (1991, p. 33) apresenta um clássico conceito de poder ao asseverar que: “[...] poder significa toda probabilidade de impor a vontade numa relação social, mesmo contra resistências, seja qual for o fundamento dessa probabilidade". Ou melhor, é a probabilidade de que uma ordem com um determinado conteúdo específico seja seguida por um dado grupo de pessoas.
} 
abordar o tema da violência e teoria social, Misse (2016) é enfático ao afirmar que a "violência" é uma palavra moderna, cujo significado difere, em toda a sua extensão semântica, do que significava antes de começos do século XX, e que, na verdade, o sentido da palavra não só não deve ser encontrado antes da modernidade como se acha, ainda em plena construção. Para ele há uma escassez teórica nos usos da violência nos discursos sociológicos contemporâneos e questiona os porquês da violência não ter se tornado um dos tópicos mais importantes da teoria social até agora (Misse, 2016).

$\mathrm{Na}$ tentativa de elaborar uma compreensão sociológica para o termo "violência", Misse considera que a violência não era um conceito e dificilmente viria a sê-lo, uma vez que trata-se de uma categoria que, deixando de ser meramente constatativa, torna-se necessariamente performática, normativa e acusatorial.

Afirma Misse (2016, p. 47):

O uso da palavra acusa um acontecimento e no mesmo ato reclama-lhe uma ação contrária. Se o uso propõe a ação violenta, logo uma justificativa lhe é cobrada. Na modernidade, ninguém pode gostar da violência: é um anátema para quem a elogia ou para quem busca apenas compreendê-la, sem condená-la. Por recobrir um sentido negativo, sua polissemia potencializa a impossibilidade de contê-la em um enunciado do tipo constatativo.

Uma vez que o tema sempre fora abordado de forma negativa e contrafactual, não surpreende, segundo Misse, a ausência da violência como um dos tópicos centrais da teoria social no século XX. Contudo, nos últimos anos um crescente investimento teórico vem sendo realizado para constituir a violência como objeto digno da teoria social. E nesse sentido, Misse (2016) inclui seus esforços na tentativa de problematizar a possibilidade teórica de uma sociologia ou de uma antropologia da violência que enfrentem a complexidade conceitual do termo.

O sociólogo neerlandês Willem Schinkel (2010), autor de um dos mais importantes estudos da violência na atualidade, ao trabalhar com o conceito de violência, a define como uma redução do ser, ou seja, a redução de uma pessoa a apenas um de seus aspectos entre tantos outros desdobramentos possíveis em uma dada situação; as alternativas são inúmeras, mas a ação violenta direcionada a essa pessoa reduz e limita o espectro de possibilidades, onde a situação desdobra-se em apenas um resultado possível. Logo, a violência a uma pessoa idosa, por exemplo, estaria por reduzir as possibilidades de ser da pessoa idosa. Quando certos valores morais, estéticos e simbólicos são considerados como legítimos e como padrões os quais toda a sociedade deve seguir, temos um caso de violência simbólica, onde o idoso é obrigado a sentir vergonha de si e abrir mão de valores que não se encaixam no padrão hegemônico, causando assim baixa autoestima e sentimentos de inferioridade e incapacidade (Schinkel, 2010).

Michel Misse ao referir-se a esse autor salienta os paradoxos contidos nos variados usos do termo "violência" nas ciências sociais:

A violência rompe com a ordem social ou a violência é constitutiva da ordem social? A violência é um problema social ou a violência é uma solução padronizada para os problemas sociais? A violência é uma forma puramente destrutiva da socialidade ou a violência é uma forma positiva de socialidade que faz as pessoas se unirem? Violência é uma forma de lidar com a contingência ou a violência é uma forma importante e fonte de contingência? Violência rompe com as normas ou a violência reforça as normas? Violência é uma situação visível ou a violência é um processo oculto? A violência do Estado é reativa em relação à violência ilegítima ou a violência do Estado é ativa em distinguir violência legítima e ilegítima? Violência é um processo social significativo, cujo sentido é posto em um referente externo ou a violência é um processo social caracterizado, exclusivamente, pela autorreferência? A violência repele ou a violência atrai? A violência é um meio para um fim ou é um fim em si mesmo? (Schinkel como citado em Misse, 2016, p. 48).

Face a impressionante lista de antinomias assevera Schinkel (2010, p. 17) que "[...] tanto a definição como a não definição da violência levam-nos a ângulos mortos em resultado dos quais certas formas de violência escapam à percepção". 
Sendo certo que, por outro lado, como adianta o mesmo autor, essa não percepção representa um mecanismo de invisibilização que, em última análise redunda em formas de aprovação e de legitimação.

Ao analisar a "disputa do conceito de violência" Michel Misse considera que a insistência por parte de diversos autores sobre o caráter abrangente e não restrito que uma teoria da violência deveria possuir enfrenta grande oposição. Cita como exemplo a reação causada pelo conceito de "violência simbólica"” de Pierre Bourdieu (1930-2002), uma vez que, para esses autores a violência física será a única a representar um modelo extremo e também porque somente a partir dessa violência física é possível pensar outras formas de violência e sua relação com o poder (Misse, 2016).

Talvez seja por esta razão que Michel Misse prefira tratar a violência não como um conceito, mas como representação social, com parte do objeto. Apesar de considerar uma solução pragmática, não busca, segundo ele, fechar um significado unívoco ou naturalizado seus usos na pesquisa empírica (Misse, 2016).

Destarte a sociologia, esteja buscando compreender, situar, conceituar, caracterizar e problematizar a violência dentro do contexto social, variadas são as formas de sua manifestação no seio dessa sociedade. Uma delas é a violência contra os idosos, violência essa muitas vezes silenciada e invisível.

\subsection{A violência e maus-tratos contra os idosos}

As violências contra a pessoa idosa podem assumir variadas formas. Podem ser visíveis ou invisíveis: as visíveis são as mortes e lesões; as invisíveis são aquelas que ocorrem sem machucar o corpo, mas provocam sofrimento, desesperança, depressão e medo. A maioria dessas últimas, segundo Minayo, Figueiredo e Mangas (2017) é incontável.

De acordo com a Secretaria dos Direitos Humanos da Presidência da República têm crescido de forma significativa as denúncias contra as violações dos direitos humanos das pessoas idosas em todo o país. As estatísticas do módulo denominado Disque 100, de fora sistemática aponta esta realidade. Contudo, a denúncia, em si, é apenas uma parte que compõe um elo muito maior. É necessário identificar cada caso, encaminhá-lo a quem de direito, e acima de tudo acompanhar as tratativas para que seu desfecho seja o mais célere e o mais efetivo possível e os idosos terem, senão os seus direitos fundamentais plenamente resguardados, ao menos o encaminhamento de suas demandas devidamente tratadas e com respostas efetivas (Brasil, 2013, 2014, 2018).

Corroborando com boa parte dos sociólogos descritos na seção anterior, Pasinato, Camarano e Machado (2006) também consideram que a violência entre seres humanos parece fazer parte da própria história da humanidade. No entanto, alguns aspectos e causas da violência são mais facilmente percebidos do que outros, com variações decorrentes em função dos valores e dos sistemas econômicos das sociedades.

$\mathrm{O}$ entendimento da violência familiar como um problema social é recente. Pesquisas acadêmicas sobre o assunto se difundiram principalmente a partir da década de 1980 (Barnett, Miller-Perrin, \& Perrin, 1997). A família e, de uma forma mais concreta, o lar/domicílio são tradicionalmente entendidos, nas mais diversas culturas, como um ambiente de amor, afeto e aconchego, um porto seguro contra a violência "externa". Contudo, é exatamente nos contextos familiares que a grande parte das violências contra os idosos ocorre (Brito, 2020; Meleiro, 2021).

Os primeiros estudos que versam sobre a violência às pessoas idosas datam de meados da década de 1970, com a publicação do artigo "Granny battered" (espancamento de avós) em 1975 (Krug, Dahlberg, Mercy, Zwi, \& Lozano, 2002). Outro momento importante para o estudo dos maus-tratos contra idosos foi a criação de uma revista dedicada exclusivamente ao tema em 1989 - Journal of Elder Abuse \& Neglect (Barnett et al., 1997).

\footnotetext{
${ }^{7}$ Violência simbólica é um conceito social elaborado pelo sociólogo francês Pierre Bourdieu, o qual aborda uma forma de violência exercida pelo corpo sem coação física, causando danos morais e psicológicos. É uma forma de coação que se apoia no reconhecimento de uma imposição determinada, seja esta econômica, social, cultural, institucional ou simbólica (Cunha, 2007).
} 
De acordo com Minayo et al. (2017), começou-se a tratar do assunto da violência contra idosos, no Brasil apenas nas duas últimas décadas, em razão especialmente de dois fatores: o primeiro em função do aumento da população idosa e, portanto, passou a ser muito mais visualizada, e por outro, em razão do protagonismo e articulação desta população no sentido de lutarem em busca da ampliação de seus direitos. Fruto desse engajamento resultaram, por exemplo, na promulgação da Política Nacional do Idoso em 1994, na criação do Estatuto do Idoso em 2003 e, posteriormente, na alteração do artigo 19 do Estatuto do Idoso, que norteia especificamente os caminhos a serem seguidos em caso de ocorrência de violência contra idosos, a Lei n 12.461 , de 26 de julho de 2011.

O conceito de violência contra a pessoa idosa adotado no Brasil é o desenvolvido pela Organização Mundial da Saúde (OMS), que assim a define:

São ações ou omissões cometidas uma vez ou muitas vezes, prejudicando a integridade física e emocional da pessoa idosa, impedindo o desempenho de seu papel social. A violência acontece como uma quebra de expectativa positiva por parte das pessoas que a cercam, sobretudo dos filhos, dos cônjuges, dos parentes, dos cuidadores, da comunidade e da sociedade em geral. (Brasil, 2014, p. 38).

O conceito de violência contra o idoso, segundo o Estatuto do Idoso segue a mesma linha da OMS e é definido como “[...] qualquer ação ou omissão praticada em local público ou privado que lhe cause morte, dano ou sofrimento físico ou psicológico" (Estatuto do Idoso, Lei n ${ }^{\circ}$ 10.741/2003, cap. IV, art.19, §1). E ainda, “[...] é dever de todos zelar pela dignidade do idoso, colocando-o a salvo de qualquer tratamento desumano, violento, aterrorizante, vexatório ou constrangedor" (Lei $\mathrm{n}^{\circ}$ 10.741/2003, Capítulo II, art. 10, § 3).

No ano de 2014 a Secretaria de Direitos Humanos da Presidência da República, elaborou o material denominado “Manual de enfrentamento à violência contra a pessoa idosa: é possível prevenir, é necessário superar”. Este trabalho foi coordenado pela socióloga, ganhadora do Prêmio de Direitos Humanos em 2014 e consultora Programas das Nações Unidas para o Desenvolvimento (PNUD), Maria Cecília de Souza Minayo. Trata-se de riquíssima fonte de consulta e dele extraiu-se os principais conceitos e tipologias de violência, maus-tratos e abusos sofridos pelos idosos.

A tipificação das violências sofridas pelos idosos, segundo o dito Manual podem ser resumidas em: abuso físico, psicológico, sexual, abandono, negligência, abusos financeiros e autonegligência.

Os abusos físicos constituem a forma de violência mais visível, segundo Minayo (2014) e caracterizam-se por empurrões, tapas, beliscões, agressões com cintos, objetos caseiros e até armas de fogo. Fatos marcantes acompanham a violência física: o local de sua ocorrência e as marcas invisíveis. De acordo com a mesma autora são nas próprias residências dos idosos ou nas de seus familiares que ocorrem a maior incidência; e quando esta violência não resulta em lesões e traumas aparentes há grande dificuldade em identificá-la, causando mais dor e sofrimento à vítima (Brasil, 2014).

Já o abuso psicológico refere-se a todas as formas de menosprezo, de desprezo, de preconceito e discriminação que trazem como consequência tristeza, isolamento, solidão, sofrimento mental e a depressão ao idoso. O abuso psicológico pode ocorrer por palavras ou por meio de atitudes e atos cujo sofrimento mental contribui, inclusive, para tentativas, ou até mesmo suicídio consumado (Minayo et al., 2010). Ressalte-se que os mais pobres, e os dependentes físicos e mentais são os mais vulneráveis a esse tipo de violência.

A violência sexual diz respeito ao ato no jogo que ocorre nas relações hétero ou homossexuais e tem por objetivo estimular o idoso ou utilizar-se dele para obter excitação sexual e práticas eróticas e pornográficas impostas por meio de aliciamento, violência física ou ameaças. Um fato que acompanha a violência sexual é que ela, na maioria das vezes não ocorre de forma isolada. Geralmente é acompanhada por violência psicológica, física e negligencias. Tal situação potencializa as consequências desse tipo de violência aumentando, inclusive, as probabilidades de tentativas de suicídio (Brasil, 2014). 
Já o abandono, na opinião da mesma autora, é uma das maneiras mais perversas de violência contra a pessoa idosa e apresenta várias facetas. A mais comum e perversa ocorre quando os próprios familiares "expulsam" o idoso de sua própria casa. Muitas vezes colocam-no em cubículos nos fundos da casa, privam-no do convívio familiar e social, e sua casa é destinada a um membro mais jovem da família. Outra forma desse tipo de violência é obrigar o idoso a ser inserido em instituição de longa permanência sem seu consentimento, muitas vezes sem o devido cuidado e zelo, privando-o de remédios e alimentos, antecipando assim a incidência de doenças e até a morte.

A negligência caracteriza-se pelas diversas maneiras de menosprezo e de abandono que os idosos sofrem. Negligência ocorrida nos serviços públicos que têm por base a impessoalidade no trato e na prestação do serviço: na área da saúde - a falta ou precariedade de assistência à saúde, - longas filas de espera para consultas e exames e com intervalos de meses entre um e outro, enquanto a saúde do idoso se deteriora, o desleixo e inoperância nos órgãos de vigilância sanitária, a inadequação e isolamento nas casas de longa permanência, no atendimento prestado pelo Instituto Nacional de Seguridade Social-INSS, nas delegacias de atenção e proteção ao idoso, nos núcleos de atenção e atendimento do Ministério Público e assim por diante. A violência causada pelos serviços de transporte público, por exemplo, é gritante. Os ônibus dão a partida e aceleram de forma tão abrupta que não são poucos os casos de lesões sofridas pelos idosos que caem, tanto dentro do ônibus, quando entram e ainda não conseguiram um assento, quanto fora, no momento em que descem. Mas não é apenas no serviço público que a negligência se instala. Ela ocorre também dentro dos lares dos idosos, Muitas vezes as casas são inadequadas, sem corrimão, pisos e tapetes escorregadios, banheiros sem proteção, favorecendo a incidência de quedas que é uma das causas de maior comorbidade em idosos.

A violência patrimonial e financeira diz respeito às disputas de familiares pela posse dos bens ou a ações delituosas cometidas por órgãos públicos e privados em relação às pensões, aposentadorias e outros bens dos idosos. Caracterizam-se geralmente pela tentativa de familiares em violar os direitos dos idosos e o forçarem a assinar procurações com o objetivo de tutela, e assim, apossarem-se de seus bens patrimoniais com o intuito de vendê-los, sem seu conhecimento. Há, contudo, formas cruéis, porém mais sutis desse tipo de violência, como a retirada dos idosos por familiares do espaço físico e social no qual sempre viveram, a retirada do cartão de benefício, especialmente daqueles idosos que possuem um grau maior de dependência, violências praticada por bancos que fazem empréstimos consignados - às vezes em conluio com familiares - sem que os idosos tenham conhecimento e tenham dado consentimento, violências causadas pelos planos de saúde ao cobrar taxas de coberturas exorbitantes, são apenas alguns exemplos desse tipo de violência.

Por fim, temos a violência autoinfligida e autonegligência. Neste caso é o próprio idoso que maltrata a si mesmo. São os casos em que ele próprio se autonegligência. Alerta Minayo (2014, p. 44) que:

[...] um dos primeiros sinais de autonegligência é a atitude de se isolar, de não sair de casa e de se recusar a tomar banho, de não se alimentar direito e de não tomar os medicamentos, manifestando clara ou indiretamente a vontade de morrer.

A autora também chama atenção para o fato de que atitudes de autodestruição realizadas pelos idosos estão associadas a processos de desvalorização que este sofre, bem como a negligências, abandonos e maus-tratos que é vítima, evidenciando que as expressões de violências de forma geral não são tomadas de forma isolada. Geralmente se manifestam de modo cumulativo e devem ser objeto de atenção.

Minayo et al. (2010) ressaltam, no entanto, que a violência doméstica e os maus-tratos a idosos não devem ser entendidos fora do contexto da violência social/estrutural em que os indivíduos e as comunidades estão inseridos. Deve-se considerar, também, as mudanças nos arranjos familiares e no papel social da mulher, a tradicional cuidadora. Discorrendo sobre o mesmo assunto, Krug et al. (2002) consideram que a forma como os maus-tratos e a violência contra idosos são 
percebidos varia entre culturas e sociedades; ressaltam os autores que em um passado não tão distante, muitas sociedades tradicionais consideravam a harmonia doméstica como um importante elemento das relações familiares. Esse papel da família era legitimado e reforçado tanto por tradições filosóficas quanto por políticas públicas, não se reconhecendo a existência de maus-tratos contra idosos e, muito menos, a sua denúncia (Krug et al., 2002). Sobre isso, Souza, Meira, Neri, Silva e Gonçalves (2004) comentam que muitas vezes, o convívio entre as gerações é imposto pelo empobrecimento da população, em especial nos grandes centros urbanos, e soma-se à sobrecarga de tarefas impostas às mulheres e à ausência de políticas públicas que auxiliem e atuem como facilitadoras das relações domésticas.

A maior importância relativa da violência social/estrutural presente em relatos dos idosos brasileiros pode estar sinalizando para uma conscientização crescente, ainda incipiente, das questões relacionadas ao processo de envelhecimento populacional e a garantia dos direitos dos idosos (Pasinato et al., 2006). Estudos recentes apontam o desconhecimento, por parte dos idosos, dos serviços que desenvolvem ações para garantia dos direitos civis e que atuam na repressão aos crimes cometidos contra eles; os idosos que dizem conhecer tais serviços, mencionam o descrédito quanto à capacidade de resolutividade (Camarano, 2004).

Pasinato et al. (2006) comentam que, por um lado, a violência contra os idosos se insere nos meandros dos conflitos intrafamiliares, muitas vezes invisíveis para a sociedade, e por outro, nas sociedades capitalistas, a própria construção do "ser idoso", que associa idade avançada à obsolescência, se traduz em violência social. Isso coloca a violência como parte de uma questão mais ampla de construção da cidadania em um ambiente democrático (Pasinato et al., 2006).

Ao discutir os avanços e contradições do Estatuto do Idoso, Camarano (2016) salienta que a essência do Estatuto está nas normas gerais que dispõem sobre a "proteção integral" aos idosos. Afirma que estes gozam de todos os direitos inerentes à pessoa humana e que o envelhecimento é um direito personalíssimo e a sua proteção, um direito social. Contudo, ainda há um vasto caminho a prosseguir. A autora acredita que a implementação efetiva do Estatuto do Idoso deverá ser pensada em um contexto mais amplo onde se leve em conta a necessidade de mecanismos de proteção social para os vários grupos etários. Não se pode perder de vista o principal amálgama social - a solidariedade - em nenhuma de suas modalidades - intergeracional, familiar e social - ao pensar mecanismos viáveis para a promoção do bem-estar social (Pasinato et al., 2006).

O filósofo e historiador italiano Norberto Bobbio (1909-2004) assegura que um dos maiores problemas em relação aos direitos do homem não está em fundamentá-los, mas em protegê-los: sem direitos reconhecidos e protegidos não há democracia e só existe cidadania quando são reconhecidos os direitos fundamentais do cidadão (Bobbio, 2004). Da mesma forma, o sociólogo e filósofo francês Edgar Morin (2010) chama atenção para o perigo da fragmentação dos saberes que criou especialistas frios, uma tecnociência arrogante e um humanismo desprezado. Morin considera impossível conhecer as partes sem conhecer o todo, tanto quanto conhecer o todo sem conhecer, particularmente, as partes. Esses princípios levam o pensamento para além de um conhecimento fragmentado que, por tornar invisíveis as interações entre um todo e suas partes anula o complexo e oculta os problemas essenciais (Morin, 2010). Em meio a toda essa discussão é importante considerar o que foi dito pela filósofa existencialista francesa, Simone de Beauvoir (1908-1986), quando afirma que "viver é envelhecer, nada mais". Também considera que não é possível pensar em uma sociedade justa para os velhos numa sociedade marcada por injustiças sociais (Beauvoir, 2018, p.227).

As ideias de Beauvoir, de certa forma vão ao encontro do pensamento sociólogo e filósofo polonês Zygmunt Bauman (1927-2017), quando considera que num mundo em que o futuro é, na melhor das hipóteses, sombrio e nebuloso, porém mais provavelmente cheio de riscos e perigos onde os laços humanos são comparados a peças de automóveis e o mundo a um contêiner cheio de objetos descartáveis - inclusive outros seres humanos -, urge a necessidade de reflexionar ativamente sobre o envelhecimento e sobre os dilemas e desafios que o envolve (Bauman, 2001). 


\section{Considerações Finais}

Quando da aprovação da Política Nacional do Idoso (PNI), em 1994, a proporção da população idosa brasileira era de aproximadamente $8 \%$. No entanto, passados vinte e cinco anos de sua aprovação, em 2021, a proporção da população idosa brasileira gira em torno de 15\%, segundo o Instituto Brasileiro de Geografia e Estatística - IBGE ${ }^{8}$, reforçando os desafios hoje impostos. Em termos absolutos estamos falando de uma população, em 1994, de 12 milhões, passando, em 2021 para 31 milhões de idosos. Ou seja, uma população quase três vezes maior, com novas demandas e desafios sociais.

As estatísticas apontam que os índices de envelhecimento em nosso país estão situados acima da média mundial e latino-americana. Como também somos um dos países mais populosos do mundo ${ }^{9}$, há a necessidade premente de enfrentar esta problemática e buscar alternativas face ao seu enfrentamento. A violência sofrida pelos idosos é uma violação de um direito humano fundamental. Compreender as razões que estão por traz dessa violência, supõe um aprofundamento sobre essas relações sociais, e sobre o contexto onde essas relações são produzidas.

A Organização Mundial de Saúde (OMS, 2015) chama atenção para a urgência de ações integradas que possibilitem melhorar a qualidade de vida das pessoas que envelhecem. Comungamos desta possibilidade, pois ações isoladas têm grandes chances de insucessos. Como país membro da ONU, o Brasil possui hoje um conjunto de leis e dispositivos que se baseiam nas Convenções Internacionais e que são da maior importância no sentido de propiciar um envelhecimento saudável, ativo e participativo. No entanto, a prática está longe da teoria da mesma forma que a intenção está longe do gesto.

Por outro lado, enfrentar esta problemática pode ser mais difícil que pareça. A análise da violência contra o idoso não se resume a um estudo eminentemente criminal. O contexto em que a mesma se desenvolve possui raízes em outros elementos, tais como falta de estrutura de apoio, conflitos familiares, questões estruturais, pobreza, ineficiência de mecanismos de acesso à justiça e outros. Tais temas são sugestões para futuras pesquisas e aprofundamento da problemática. Por isso é necessário que se tenha uma visão mais ampliada, que permita a percepção de que o enfrentamento da violência contra o idoso ultrapassa a análise criminal e exige a aplicação dos princípios que norteiam a política nacional, tal como balizados na Lei no 8.842/1994.

As várias formas de violências sofridas pelos idosos brasileiros constituem práticas sociais de violação de direitos consagrados na Constituição da República de 1988 e no Estatuto do Idoso. Portanto, é necessário resguardar e proteger os direitos dos idosos. Apesar das inúmeras possibilidades e contextos em que se originam, as várias expressões de violências podem ser devidamente tratadas, prevenidas e reduzidas. Sendo assim, estratégias de enfrentamento precisam ser pensadas e postas em prática; e por fim, e não menos importante, porque as ações que levam à superação da violência e contribuem para que os idosos usufruam de seus plenos direitos estão em consonância com o que preconizou o Ano Internacional do Idoso, proclamado pela ONU, em 1999: "uma sociedade para todas as idades" (ONU, 1999).

Não basta aspirar pelo envelhecimento da população. É necessário que a sociedade como um todo esteja ciente dessa realidade e que autoridades competentes, gestores públicos e privados, universidades, sociedade civil organizada, arranjos familiares e demais instituições encontrem os caminhos que promovam o respeito à sabedoria e à experiência e que levem a uma vida sem violência para nossos idosos. Dessa forma estaremos ampliando nosso patrimônio democrático, ético e cultural.

\section{Referências}

Adorno, S. (1993). A criminalidade urbana violenta: um recorte temático. BIB - Revista Brasileira de Informação Bibliográfica em Ciências Sociais, (35), 3242.

Aron, R. (1967). Les étapes de la pensée sociologique. Gallimard.

Barnett, O., Miller-Perrin, C. L. \& Perrin, R. D. (1997). Family violence across the lifespan: an introduction. Sage Publications.

${ }^{8}$ https://www.ibge.gov.br/apps/populacao/projecao/index.html

${ }^{9}$ Dos 193 países do mundo, o Brasil é o quinto mais populoso. Fica atrás apenas da China Índia, Estados Unidos e Indonésia. 
Research, Society and Development, v. 10, n. 5, e11310514006, 2021

(CC BY 4.0) | ISSN 2525-3409 | DOI: http://dx.doi.org/10.33448/rsd-v10i5.14006

Bauman, Z. (2001). Modernidade Líquida (P. Dentzien, Trad.). Zahar.

Beauvoir, S. (2018). A velhice M. H. S. Martins, Trad., (2a ed). Nova Fronteira.

Bobbio, N. (2004). A era dos direitos (C. N. Coutinho, Trad.). Elsevier.

Brasil. (2013). Respeito. Direito da Pessoa Idosa. Responsabilidade de todos. SDH.

Brasil. (2014). Brasil: manual de enfrentamento à violência contra a pessoa idosa. É possível prevenir. É necessário superar. SDH.

Brasil. (2018). Estatísticas do Disque 100. http://www.mdh.gov.br/informacao-ao-cidadao/ouvidoria/balanco-disque-100

Bretas, M. L. (1991). O crime na historiografia brasileira: uma revisão na pesquisa recente. BIB - Revista Brasileira de Informação Bibliográfica em Ciências Sociais, (32), 49-61.

Brito, K. M. S.M (2020). Rotas críticas de mulheres idosas em situação de violência: O caminho percorrido até o atendimento na rede de proteção. Orientador: Patrícia Krieger Grossi. 2020. 156 f. Tese (Doutorado em Gerontologia Biomédica) - Faculdade me Medicina, PUC/RS.

Camarano, A. A. (2004). Os novos idosos brasileiros: muito além dos 60. Ipea.

Camarano, A. A. (2016). Introdução. In: Alcântara, A. O., Camarano, A. A., Giancomin, K. C. (Orgs.). Política Nacional do Idoso: velhas e novas questões. Ipea.

Centro Latinoamericano y Caribeño de Demografía. (2014). La nueva era demográfica en América Latina y el Caribe. La hora de la igualdad según el reloj poblacion. http://www.cepal.org/celade/noticias/paginas/6/53806/MPD_ddr2_esp.pdf

Comissão Econômica para a América Latina e o Caribe. (2013a). O futuro do envelhecimento no Brasil. Datas emblemáticas e opções de política: perspectivas para 2040 e mais adiante. http://www.cepal.org/celade/noticias/documentosdetrabajo/0/51990/Folleto_Brasil.pdf

Comissão Econômica para a América Latina e o Caribe. (2013b). Estimaciones y proyecciones de población a largo plazo 1950-2100. http://www.cepal.org/es/estimaciones-proyecciones-poblacion-largo-plazo-1950-2100

Constituição da República Federativa do Brasil de 1988. http://www.planalto.gov.br/ccivil_03/constituicao/constituicao.htm

Cunha, T. R. A. (2007). O preço do silêncio: mulheres ricas também sofrem violência. Edições Uesb.

Elias, N. (1990). O processo civilizador: uma história dos costumes (Vol. I). Jorge Zahar.

Elias, N. (1993). O processo civilizador: formação do Estado e civilização (Vol. II). Jorge Zahar.

Gebara, A. \& Lucena, R. F. (2005). O poder e cotidiano: breve discussão sobre o poder para Norbert Elias. Anais do IX Simpósio Internacional Processo Civilizador - Tecnologia e Civilização. Ponta Grossa, PR, Brasil. http://www.pg.cefetpr.br/ppgep/Ebook/cd_Simpósio/artigos.

Hobbes, T. (2003). Leviatã ou matéria forma e poder de um Estado eclesiástico e civil (J. P. Monteiro e M. N. Silva, Trads.). Martins Fontes.

Instituto Brasileiro de Geografia e Estatística. (2017). Síntese de indicadores sociais: uma análise das condições de vida da população brasileira. IBGE.

Instituto de Pesquisa Econômica Aplicada. (2016). Política nacional do idoso: velhas e novas questões. Organizado por A. O. Alcântara, A. A. Camarano e K. C. Giacomin. IPEA.

Krug, E. G., Dahlberg, L. L., Mercy, J. A., Zwi, A. B. \& Lozano, R. (2002). World report on violence and health. WHO.

Marconi, M. A., Lakatos, E. M. (2017). Metodologia do trabalho científico: projetos de pesquisa / pesquisa bibliográfica/ teses de doutorado, dissertações de mestrado, trabalhos de conclusão de curso (8a ed.). Atlas.

Lei $n^{\circ}$ 8.842, de 04 de janeiro de 1994. Dispõe sobre a política nacional do idoso, cria o Conselho Nacional do Idoso e dá outras providências. Brasília.

Lei . $^{\circ} 10.741$, de $1 .^{\circ}$ de outubro de 2003. Dispõe sobre o Estatuto do Idoso e dá outras providências. Brasília.

Lei.$^{\circ} 12.461$, de 26 de julho de 2011. Altera a Lei no 10.741, de 10 de outubro de 2003, para estabelecer a notificação compulsória dos atos de violência praticados contra o idoso atendido em serviço de saúde. Brasília.

Lima, R. K., Misse, M., Miranda, A. P. M. (2000). Violência, criminalidade, segurança pública e justiça criminal no Brasil: uma bibliografia. BIB - Revista Brasileira de Informação Bibliográfica em Ciências Sociais, (50), 45-123.

Meleiro, M. L. A. P. (2021). A rede de proteção e enfrentamento da violência contra a pessoa idosa em Manaus: avanços e desafios. Orientador: Izaura Rodrigues Nascimento. 2021. 169 f. Dissertação) (Mestrado em Segurança Pública, Direitos Humanos e Cidadania) - Universidade do Estado do Amazonas EUA/AM.

Minayo (2014). O desafio do conhecimento: pesquisa qualitativa em saúde (14a ed). Huitec.

Minayo, M. C. S., Souza, E. R. \& Paula, D. R. (2010). Revisão sistemática da produção acadêmica brasileira sobre causas externas e violências contra a pessoa idosa. Ciência \& Saúde Coletiva, 15(6), 2709-2718. 
Research, Society and Development, v. 10, n. 5, e11310514006, 2021

(CC BY 4.0) | ISSN 2525-3409 | DOI: http://dx.doi.org/10.33448/rsd-v10i5.14006

Minayo, M. C. S., Figueiredo, A. E. B. \& Mangas, R. M. N. (2017). O comportamento suicida de idosos institucionalizados: histórias de vida. Physis, 27(4), 981-1002.

Misse, M. (2016). Violência e teoria social. Dilemas - Revista de Estudos de Conflito e Controle Social, 9(1), 45-63.

Misse, M., Silva, L. A. M., Leite, M. P., Véran, J-F., Vargas, J. D. \& Werneck, A. (2009). Violência, sujeito e sociologia - Entrevista com Michel Wieviorka. Dilemas - Revista de Estudos de Conflito e Controle Social, 2(3), 143-172.

Morin, E. (2010). A cabeça bem feita: repensar a reforma, reformar o pensamento (18a ed.). Bertrand Brasil.

Odália (1983). O que é a violência (Coleção primeiros passos). Editora Brasiliense.

Organização das Nações Unidas. (1999). Uma sociedade para todas as idades: ano internacional dos idosos. ONU.

Organização Mundial da Saúde. (2015). Relatório Mundial de Envelhecimento de Saúde. https://sbgg.org.br/wp-content/uploads/2015/10/OMSENVELHECIMENTO-2015-port.pdf

Foucault, M. (1997). Vigiar e punir: história das violências nas prisões (L. M. P. Machado, Trad.). Vozes.

Pasinato, M. T., Camarano, A. A. \& Machado, L. (2006). Idosos vítimas de maus-tratos domésticos: estudo exploratório das informações levantadas nos serviços de denúncia. Textos para Discussão, (1200), 1-36.

Programa das Nações Unidas para o Desenvolvimento. (2017). Relatório anual Brasil 2017. http://www.br.undp.org/content/dam/brazil/docs/public acoes/relatorio-pnud-brasil-2017.pdf

Resolução $O N U n^{\circ}$ 217-A, de 10 de dezembro de 1948. Norma federal. http://www.normasbrasil.com.br/norma/resolucao-217-1948_94854.html

Sallas, A. L. F. (2001). Resenha do livro Os estabelecidos e os outsiders. Campos: Revista de Antropologia Social, 1, $217-220$.

Santos, J. V. T. (2004). Violências e dilemas do controle social nas sociedades da "modernidade tardia". São Paulo em Perspectiva, 18 (1), 3-12.

Schinkel, W. (2010). Aspects of violence: A critical theory. Palgrave Macmillian.

Souza, A. S., Meira, E. C., Neri, I. G., Silva, J. A. \& Gonçalves, L. H. (2004). Fatores de risco de maus-tratos ao idoso na relação idoso/cuidador em convivência familiar. Textos sobre Envelhecimento, 7(2).

Sposito, M. P. (2001). Um breve balanço da pesquisa sobre violência escolar no Brasil. Educ Pesq, 27(1), 87-103.

Weber, M. (1991). Economia e sociedade: Fundamentos da sociologia compreensiva. Editora UnB.

Wieviorka, M. (2018). Entrevista de Michel Wieviorka, sociólogo [Arquivo de vídeo]. https://youtu.be/EMRNq1opNMA

Zaluar, A. (1999). Violência e crime. In S. Miceli (Org.), O que ler na ciência social brasileira (1970-1995), 13-107. Anpocs. 